\title{
Trilhando caminhos de inovação e solidariedade: a vida e obra de Jan Blommaert
}

\author{
Joel Windle ${ }^{1}$ \\ Daniel N. Silva ${ }^{2}$
}

Resumo: Apresentamos as contribuições e trajetória de Jan Blommaert (1961-2021), sociolinguista belga que trabalhou nas interfaces entre os estudos da linguagem, antropologia e sociologia. Sua principal contribuição teórica foi no desenvolvimento do campo da sociolinguística da globalização (BLOMMAERT, 2010), mas ele se destacou também pela amplitude de sua produção científica e pelo diálogo que manteve com pesquisadores ao redor do mundo. Numa perspectiva etnográfica, Blommaert contribuiu para o refinamento de conceitos como ideologia linguística, superdiversidade, indexicalidade, entextualização, escala e cronotopo, entre outros. Suas pesquisas empíricas contemplaram políticas linguísticas na Tanzânia, a recepção de imigrantes na Europa, novas formas de interação on-line e formas emergentes de autoritarismo político. Os estudos da linguagem brasileiros foram inelutavelmente afetados pelo trabalho de Blommaert - e a sua proposta de estudo de formas emergentes da interação, do discurso e da linguagem certamente ainda renderá muitos frutos. Seu legado, visível não apenas em uma produção acadêmica prolífica mas também em relações sociais intencionalmente igualitárias, sobreviverá por um tempo duradouro.

Palavras-chave: Jan Blommaert. Sociolinguística. Antropologia linguística. Etnografia. Discurso.

an Blommaert (1961-2021) foi um dos sociolinguistas mais influentes e inovadores do final do século XX e início do século

1 Professor do Departamento de Letras Estrangeiras Modernas e do Programa de Pós-Graduação em Estudos de Linguagem da Universidade Federal Fluminense. Coordena o Núcleo de Estudos Críticos em Linguagens, Educação e Sociedade (NECLES). Possui graduação em Letras (inglês e francês, BA (Hons) pela Universidade de Melbourne (2001); Graduate Diploma of Education (2002) pela Universidade de Melbourne e Doutorado em Educação em cotutela pelas Universidades de Melbourne e Bourgogne (2008).

2 Professor de pragmática, linguística aplicada e sociolinguística da Universidade Federal de Santa Catarina e do Programa Interdisciplinar em Linguística Aplicada da Universidade Federal do Rio de Janeiro. Desenvolve pesquisas sobre significação, violência e resistência política a partir de pesquisa de campo no Complexo do Alemão/RJ e outros territórios. É co-editor de Trabalhos em Linguística Aplicada e Pragmatics. É editor associado de DELTA e membro do comitê editorial de Language in Society. Em 2021, co-editou, com Jacob Mey, o livro "The pragmatics of Adaptability" (John Benjamins). 
XXI. Sua principal contribuição teórica foi no desenvolvimento do campo da sociolinguística da globalização (BLOMMAERT, 2010), mas ele se destacou também pela amplitude de sua produção científica e pelo diálogo que manteve com pesquisadores ao redor do mundo. Esse diálogo, além de um propósito acadêmico, fez parte de um claro projeto político em favor da justiça social e da democratização do conhecimento. Suas ideias foram amplamente debatidas por seus pares, e pelo próprio Blommaert, que reavaliava frequentemente os conceitos por ele empregados e refinados em sua pesquisa, tais como escala, cronotopo e indexicalidade (ver, por exemplo, BLOMMAERT, 2015; BLOMMAERT; WESTINEN; LEPPANEN, 2015).

Nascido na Bélgica, Blommaert concluiu seu doutorado em 1989 na Universidade de Ghent, onde mais tarde foi docente. Ele também trabalhou nas Universidades de Antuérpia (Bélgica), Londres (Inglaterra), Jyvaskyla (Finlândia) e Tilburg (Holanda). Ele era diretor do centro de pesquisa Babylon, na Universidade de Tilburg, quando adoeceu com câncer e faleceu, ainda jovem, com 59 anos, no dia 7 de janeiro de 2021.

Blommaert realizou pesquisa de campo para o doutorado na Tanzânia na década de 1980. Sua tese deu origem ao livro State Ideology and Language in Tanzania, publicado originalmente em 1999 e revisado a partir de uma nova visita de campo a Dar es Salaam, a principal cidade do país, em 2012 (ver BLOMMAERT, 2014). Nele, Blommaert analisa a dinâmica do planejamento linguístico após a independência do domínio colonial que durou mais de quatro séculos. No contexto da descolonização na década de 1960, o suaíli foi planejado como língua nacional no projeto de unificação do país. Em um país superdiverso linguisticamente, o fato de o suaíli - "a língua que incorporou e articulou a independência e, depois, a revolução socialista" (BLOMMAERT, 2014, p. 2) - ser usado como primeira ou segunda língua por quase toda a população é conhecido na literatura sociolinguística como uma conquista de sucesso em termos de 
planejamento linguístico. A opinião profissional de sociolinguistas sobre esse fato bem-sucedido, no entanto, não correspondia aos comentários cotidianos que Blommaert escutava em Dar es Salaam e outras cidades do país. Intelectuais, políticos e mesmo linguistas locais reclamavam com Blommaert que a expansão do suaíli era falha e não correspondia aos propósitos desejados. A resposta que o autor encontrou para esse paradoxo era a de que o descontentamento era, na verdade, um efeito linguísticoideológico: embora houvesse um sucesso empírico da profusão do suaíli socialmente, a língua não era percebida por seus planejadores como o artefato homogêneo que permitiria a implementação do projeto socialista unificado. Nesse estudo do início de sua carreira, Blommaert deu uma decisiva contribuição aos campos da sociolinguística e antropologia linguística ao demonstrar o papel dos comentários metapragmáticos na percepção da diversidade linguística, bem como da centralidade dos processos de formação de registros (AGHA, 2007) - ou correlações entre formas de falar e imagens de pessoa - no estudo da variação e política sociolinguísticas.

Em 2007, ele retomou seus estudos sobre formas de autoridade e legitimidade de diferentes tipos de texto e de letramento na região central da África, resumidos na obra Grassroots Literacy (BLOMMAERT, 2008). Como a produção do autor viria a ser reconhecida, a repercussão dessa obra se deveu sobretudo ao rigor no diálogo com a literatura existente, à importância atribuída por ele ao trabalho empírico e etnográfico e às conclusões críticas derivadas de um processo de intensa atenção à agência, à mobilidade e à complexidade. $\mathrm{Na}$ esteira de sociolinguistas pioneiros/ as como Dell Hymes, John Gumperz, Jane Hill e Deborah Cameron, Blommaert contribuiu para o aperfeiçoamento de uma abordagem etnográfica ao estudo dos textos e da interação, oferecendo reflexões metodológicas para a pesquisa de campo (ver BLOMMAERT; JIE, 2011; BLOMMAERT, 2018) e a análise do discurso (ver BLOMMAERT, 2015). 
Com Jef Verschueren, Blommaert estudou discursos de intolerância à migração na Europa (ver BLOMMAERT; VERSCHUEREN, 1998). Tal pesquisa da década de 1990 sobre ideologias linguísticas nacionalistas na Bélgica foi uma importante contribuição ao projeto coletivo de desenvolver o conceito de ideologia linguística, proposto por Michael Silverstein (1979). Liderado por sociolinguistas e antropólogos/as, como Bambi Schieffelin, Katryn Woolard e Paul Kroskrity, esse movimento de trazer a reflexividade leiga ou nativa sobre a língua para dentro dos estudos da linguagem tem produzido importantes trabalhos sobre o funcionamento da linguagem situada (ver SCHIEFFELIN, WOOLARD; KROSKRITY, 1998), o que no Brasil tem produzido importantes inovações nos estudos sobre linguagem e sociedade (ver SIGNORINI, 2008, e MOITA LOPES, 2013, para duas obras pioneiras no Brasil nessa direção).

Blommaert também é conhecido como um importante estudioso do tema das migrações. Em sua prolífica produção, ele analisou como os sentidos produzidos no discurso ganham ou perdem força em processos de avaliação de pedidos de asilo na Europa (ver, por exemplo, BLOMMAERT, 2001). Apoiando-se no caráter regrado e ordenado da noção de indexicalidade (ver BLOMMAERT; SILVA, 2020), Blommaert mostra como o poder social se manifesta nas condições de desigualdade interacional. Com esse enfoque, ele dialogou com vários dos grandes teóricos sociais, tais como Marx, Durkheim, Bourdieu, Foucault, Bakhtin e Goffman. Ele foi, de fato, um grande leitor, tendo revisitado diversas tradições disciplinares, além de ter delineado importantes pontos de contato e de integração de ideias entre a sociologia, a antropologia e a linguística.

Na última etapa da sua carreira, Blommaert se dedicou às mudanças recentes nas formas de comunicação e mobilidade de pessoas e signos na era da globalização. Com seu olhar para a língua dentro das relações sociais e as trocas de sentido produzidas pelo deslocamento (ver o conceito de entextualização em BLOMMAERT; SILVA, 2020), Blommaert trabalhou 
diligentemente com a noção de superdiversidade (BLOMMAERT; RAMPTON, 2011; BLOMMAERT, 2013; VERTOTEC, 2007; DUBOC; FORTES, 2020). Esse conceito tem sido intensamente debatido no Brasil, sobretudo a partir do consórcio de universidades que organizou a Escola de Altos Estudos em Linguagem e Sociedade, na Unicamp e na UNIRIO, em agosto de 2015, resultando no dossiê "Linguagem e sociedade: mobilidade, multilinguismo e globalização", publicado no volume $42 \mathrm{da}$ Revista da ANPOLL em 2016 (ver SIGNORINI; CAVALCANTI; MAHER, 2016). É importante notar que a proposta original de superdiversidade de Vertotec (2007) e do próprio Blommaert vem sendo criticada. Marco Jacquemet (2015, p. 341) resume alguns pontos da crítica: segundo o autor, os críticos "fazem objeção à falta de clareza teórica ao pouco engajamento com a teoria política, com o viés eurocêntrico metropolitano e a uma certa euforia neoliberal, exemplificada pelo prefixo 'super"' No entanto, a pesquisa do próprio Jacquemet - um parceiro de pesquisa de longa data de Jan Blommaert! - revela a importância conceitual e empírica do construto superdiversidade, uma vez que "o mundo está agora repleto de contextos em que falantes desterritorializados usam uma mistura de línguas ao interagir com a família, amigos e colegas de trabalho; leem inglês e outras línguas 'globais' na tela do computador" (JACQUEMET, 2015, p. 341); essas pessoas também se engajam em diversas práticas culturais híbridas e translíngues, mediadas pelas tecnologias digitais. Além disso, a pesquisa coordenada por Joel Windle, da qual participam Daniel Silva e outros/as colaboradores/ as, demonstra o caráter superdiverso e cosmopolita das interações on-line e off-line de sujeitos das periferias brasileiras (ver WINDLE et al., 2019). Esse cosmopolitismo periférico demonstra a importância de mobilizar os modos de teorizar e olhar para a realidade empírica propostos por Blommaert.

É importante ter em vista que, se de um lado a primeira geração de teorias da globalização, muitas vezes, adotou uma postura otimista 
de fluxos e trocas sem limites, Blommaert sempre alertou para as hierarquias, desigualdades e formas de opressão veiculadas também pelas novas condições globais (ver BLOMMAERT, 2010). Essa perspectiva ganhou espaço no Brasil em programas e projetos orientados para uma visão crítica e etnográfica da relação entre língua e sociedade, como o Programa Interdisciplinar em Linguística Aplicada da UFRJ, onde se encontra a maior concentração de teses e dissertações que mobilizam o trabalho de Blommaert. Sua preocupação com usos das novas tecnologias de comunicação, como Twitter, dentro de projetos políticos autoritários, coloca a produção de Blommaert ainda mais perto das preocupações atuais de linguistas brasileiros dentro do cenário atual (ver BLOMMAERT, 2020).

Blommaert era famoso por ser workaholic, cultivando muitas parcerias de pesquisa, apresentando trabalhos em eventos acadêmicos e publicando prolificamente. Ele disponibilizou sua produção inteira em plataformas de livre acesso, como Academia.edu, e em sites institucionais no formato de Working Paper (Tilburg Papers in Culture Studies). Assim, ele se esforçou ativamente por tornar sua produção acessível a todos, o que para ele era um princípio central da democratização da ciência e da universidade. Ele também incentivou os demais colegas a divulgar seu trabalho da mesma maneira, argumentando que nem as revistas mais conceituadas da sociolinguística têm fator de impacto relevante. Para Blommaert, o mais importante é a circulação das produções, não o nome ou reputação da revista que seleciona e publica. Com a pressão das classificações nacionais e internacionais, essa visão marca Blommaert como um democrata radical que, de alguma maneira, encontra no sistema brasileiro de revistas não-comerciais de livre acesso algo a ser valorizado.

No plano pessoal, Blommaert deixa sua esposa, Pika, e dois filhos no início da vida adulta. Colegas que os visitavam em Antuérpia são unânimes ao relatar a hospitalidade com que eram recebidos/as. Pika é natural de Antuérpia e gosta de partilhar com seus visitantes o vasto conhecimento da 
obra do pintor Rubens, cujas pinturas são parte inequívoca do patrimônio cultural da cidade. Nas manifestações de pesar, linguistas e antropólogos/ as de diferentes partes do mundo exibiram fotos de visível bem-estar e afeto ao lado de Jan e Pika.

Jan Blommaert deixou bastante claro seu compromisso com o combate à desigualdade. Ele fez questão em dialogar com pesquisadores da "periferia" do capitalismo, como a África, o Oriente Médio e a América do Sul. A opção de Blommaert de direcionar uma de suas últimas contribuições ao público brasileiro, por meio de entrevista gravada com Daniel N. Silva, certamente não foi por acaso, testemunhando a sua vontade de diálogo com pesquisadores e com as pessoas do Brasil (ver BLOMMAERT; SILVA, 2020).

É com bastante pesar que testemunhamos a partida prematura de um grande sociolinguista, mas antes de tudo de um grande ser humano, que acreditava no valor da democracia. Acreditamos que o seu legado, visível não apenas em uma produção acadêmica prolífica mas também em relações sociais intencionalmente igualitárias, sobreviverá por um tempo duradouro. Os estudos da linguagem brasileiros foram inelutavelmente afetados pelo trabalho de Blommaert - e a sua proposta de estudo de formas emergentes da interação, do discurso e da linguagem certamente ainda renderá muitos frutos no ambiente acadêmico brasileiro.

\section{Referências}

AGHA, Asif. Language and social relations. Cambridge: Cambridge University Press, 2007.

BLOMMAERT, Jan. Political discourse in post-digital societies. Trabalhos em Linguística Aplicada, v. 59, n. 1, p. 390-403, 2020. 
. Dialogues with Ethnography: Notes on classics, and how I read them. Bristol: Multilingual Matters, 2018.

. State ideology and language in Tanzania. Edinburgh: Edinburgh University Press, 2014.

. Ethnography, Superdiversity and Linguistic Landscapes: Chronicles of Complexity. Bristol: Multilingual Matters, 2013.

. Chronotopes, Scales, and Complexity in the Study of Language in Society. Annual Review of Anthropology, v. 44, p. 105-116, 2015.

.Grassroots Literacy: Writing, Identity and Voice in Central Africa. London: Routledge, 2008.

.The Sociolinguistics of Globalization. Cambridge: Cambridge University Press, 2010.

- Discourse: A Critical Introduction. Cambridge: Cambridge University Press, 2005

. Investigating narrative inequality: African asylum seekers' stories in Belgium. Discourse \& Society, v. 12, n. 4, p. 413-49, 2001.

BLOMMAERT, Jan; JIE, D. Ethnographic Fieldwork: An Introduction. Bristol: Multilingual Matters, 2011.

BLOMMAERT, Jan; RAMPTON, Ben. Language and Superdiversity. Diversities, v. 13, n. 2, p. 1-21, 2011.

BLOMMAERT, Jan; SILVA, Daniel. Entrevista com Jan Blommaert: 30 Anos da Associação de Linguística Aplicada do Brasil (ALAB). Canal da ALAB no Youtube, 2020. Disponível em: https://www.youtube.com/ 
watch?v=LPwxX6fDgh0\&t=311s Acesso em: 31 jan. 2021.

BLOMMAERT, Jan; VERSCHUEREN, Jef. The Role of Language in European Nationalist Ideologies. In: SCHIEFFELIN, Bambi; WOOLARD, Katryn; KROSKRITY, Paul (Orgs.). Language Ideologies: Practice and Theory. Oxford: Oxford University Press, 1998, p. 189-210.

BLOMMAERT, Jan; WESTINEN, Elina.; LEPPANEN, Sirpa. Further notes on sociolinguistic scales. Intercultural Pragmatics, v. 12, n. 1, p. 119-127, 2015.

DUBOC, Anna; FORTES, Olívia. Superdiversidade, linguagem e sociedade: questões em curso. Entrevista com Jan Blommaert e Massimiliano Spotti (Tilburg University). Educação e Pesquisa, v. 45, 2020.

JACQUEMET, Marco. Language in the Age of Globalization. In: BONVILLAIN, Nancy (Org.). The Routledge Handbook of Linguistic Anthropology. Londres: Routledge, 2015, p. 329-347.

MOITA LOPES, Luiz Paulo Org. O português no século XXI: cenário geopolítico e sociolinguístico. São Paulo: Parábola, 2013.

SCHIEFFELIN, Bambi; WOOLARD, Katryn; KROSKRITY, Paul. Orgs. Language Ideologies: Practice and Theory. Oxford: Oxford University Press, 1998.

SIGNORINI, Inês. Org. Situar a língua(gem). São Paulo: Parábola, 2008

SIGNORINI, Inês; CAVALCANTI, Marilda; MAHER, Terezinha. Apresentação: Selected Papers on Language and Society: Mobility, Multilingualism, and Globalization. Revista da Anpoll, v. 1, n. 40, p. 5-15, 2016. 
SILVERSTEIN, Michael. 1979. Language structure and linguistic ideology. In: P. Clyne, W. Hanks \& C. Hofbauer. Eds. The elements: a parasession on linguistic units and levels. Chicago: Chicago Linguistic Society. p. 193-247.

VERTOTEC, Steven. Super-diversity and its implications. Ethnic and Racial Studies, v. 30, n. 6, p. 1024-1054, 2007.

WINDLE, Joel; SOUZA, Ana Lúcia; SILVA, Daniel; ZAIDAN, Junia; MAIA, Junot; MUNIZ, Kassandra; LORENSO, Silvia. Por um paradigma transperiférico: uma agenda para pesquisas socialmente engajadas. Trabalhos em Linguística Aplicada, v. 9, n. 2, p. 1563-1576.

Tracing pathways of innovation and solidarity: the life and work of jan blommaert

\begin{abstract}
We present the contributions and trajectory of Jan Blommaert (19612021), a Belgian sociolinguist who worked at the intersections of language studies, anthropology and sociology. His main theoretical contribution was in the development of the field of the sociolinguistics of globalization (BLOMMAERT, 2010), but he also stood out for the breadth of his scientific production and for the dialogue he maintained with researchers around the world. Using an ethnographic lens, Blommaert contributed to refining concepts such as linguistic ideology, superdiversity, indexicality, entextualization, scale and chronotope, among others. His empirical research included language policies in Tanzania, the reception of immigrants in Europe, new forms of online interaction and emerging forms of political authoritarianism. Brazilian language studies have been strongly affected by Blommaert's work - and his project of studying emerging forms of interaction, discourse and language will certainly continue to bear fruit. His legacy, visible not only in prolific academic production but also in intentionally egalitarian social relations, will make a lasting impact.
\end{abstract}

Keywords: Jan Blommaert. Sociolinguistics. Linguistic Anthropology. Ethnography. Discourse.

Recebido em: 23/02/2021

Aceito em: 06/04/2021 


\section{Tradução}

Multilinguismo, discurso e direitos linguísticos 